\title{
Clinical and Neurocognitive Characterization of a Family With a Novel MED12 Gene Frameshift Mutation
}

Gaetan Lesca, ${ }^{1,2 *}$ Marie-Pierre Moizard, ${ }^{3,4}$ Gerald Bussy, ${ }^{5}$ Dominique Boggio, ${ }^{1}$ Hao Hu, ${ }^{6}$ Stefan A. Haas, ${ }^{7}$ Hans-Hilger Ropers, ${ }^{6}$ Vera M. Kalscheuer, ${ }^{6}$ Vincent Des Portes, ${ }^{5}$ Audrey Labalme, ${ }^{1}$ Damien Sanlaville, ${ }^{1,2}$ Patrick Edery, ${ }^{1,2}$ Martine Raynaud, ${ }^{3,4}$ and James Lespinasse ${ }^{8}$

${ }^{1}$ Service de Génétique and Centre de Référence des Anomalies du Développement, Hôpital Femme Mère Enfant, Hospices Civils de Lyon, Lyon, France

${ }^{2}$ INSERM U1028, CNRS, UMR5292, Lyon Neuroscience Research Center, TIGER Team, University Claude Bernard Lyon 1, Université de Lyon, Lyon, France

${ }^{3}$ INSERM U930, Tours, France

${ }^{4}$ Service de Génétique, CHRU de Tours, Tours, France

${ }^{5}$ Centre de Référence pour les Déficiences Intellectuelles Liées à l’X, Hôpital Femme Mère Enfant, Lyon, France

${ }^{6}$ Department of Human Molecular Genetics, Max Planck Institute for Molecular Genetics, Berlin, Germany

'Department of Computational Biology, Max Planck Institute for Molecular Genetics, Berlin, Germany

${ }^{8}$ Laboratoire de Génétique Chromosomique, Hôpital de Chambéry, Chambéry, France

Manuscript Received: 25 March 2013; Manuscript Accepted: 8 July 2013

FG syndrome, Lujan syndrome, and Ohdo syndrome, the MaatKievit-Brunner type, have been described as distinct syndromes with overlapping non-specific features and different missense mutations of the MED12 gene have been reported in all of them. We report a family including $\mathbf{1 0}$ males and 1 female affected with profound non-specific intellectual disability (ID) which was linked to a 30-cM region extending from Xp11.21 (ALAS2) to Xq22.3 (COL4A5). Parallel sequencing of all X-chromosome exons identified a frameshift mutation (c.5898dupC) of MED12. Mutated mRNA was not affected by non-sense mediated RNA decay and induced an additional abnormal isoform due to activation of cryptic splice-sites in exon 41. Dysmorphic features common to most affected males were long narrow face, high forehead, flat malar area, high nasal bridge, and short philtrum. Language was absent or very limited. Most patients had a friendly personality. Cognitive impairment, varying from borderline to profound ID was similarly observed in seven heterozygous females. There was no correlation between cognitive function and X-chromosome inactivation profiles in blood cells. The severe degree of ID in male patients, as well as variable cognitive impairment in heterozygous females suggests that the duplication observed in the present family may have a more severe effect on MED12 function than missense mutations. In a cognitively impaired male from this family, who also presented with tall stature and dysmorphism and did not have the MED12 mutation, a $600-\mathrm{kb}$ duplication at 17p13.3 including the YWHAE gene, was found in a mosaic state. $\odot 2013$ Wiley Periodicals, Inc.

Key words: intellectual deficiency; X-linked; MED12; 17p13.3; YWHAE
How to Cite this Article:

Lesca G, Moizard M-P, Bussy G, Boggio D, $\mathrm{Hu}$ H, Haas SA, Ropers H-H, Kalscheuer VM, Des Portes V, Labalme A, Sanlaville D, Edery P, Raynaud M, Lespinasse J. 2013. Clinical and neurocognitive characterization of a family with a novel MED12 gene frameshift mutation.

Am J Med Genet Part A 161A:3063-3071.

Conflict of interest: none.

Grant sponsor: German Ministry of Education and Research (MRNET); Grant number: 01GS08161; Grant sponsor: European Union Framework Program 7 (FP7) (Project GENCODYS); Grant number: 241995.

*Correspondence to:

Gaetan Lesca, M.D., Ph.D., Service de Cytogénétique Constitutionnelle, Groupement Hospitalier Est, 59 Boulevard Pinel, 69677 Bron Cedex, France.

E-mail: gaetan.lesca@chu-lyon.fr Article first published online in Wiley Online Library (wileyonlinelibrary.com): 16 August 2013

DOI 10.1002/ajmg.a.36162 


\section{INTRODUCTION}

Intellectual disability (ID) affects $1-3 \%$ of the population and is characterized by impaired cognitive function and adaptive behavior with onset in childhood. The causes of ID are extremely diverse. $\mathrm{X}$-linked forms of ID (XLID) may be identifiable through their characteristic inheritance pattern. For many years, the ID-causative genes were mapped using linkage analysis in large XLID families [Ropers, 2008]. Identification of genes causing non-syndromic XLID has long been challenging because in many families linkage intervals were large and often harbored a plethora of candidate genes. During the last years, high-throughput next generation sequencing greatly facilitated the discovery of rare, disease-causing sequence variants.

Up to now, germline mutations of MED12 have been found in three distinct XLID syndromes, namely FG syndrome (FGS), Lujan syndrome (LS), and Ohdo syndrome, the Maat-Kievit-Brunner type (OSMKB) [Risheg et al., 2007; Schwartz et al., 2007; Vulto-van Silfhout et al., 2013]. FGS, also known as Opitz-Kaveggia syndrome
(OMIM 305450) is characterized by ID, hypotonia, dysmorphic facial features, broad thumbs and halluces, constipation and agenesis of the corpus callosum (ACC) [Opitz and Kaveggia, 1974]. LS, also called Lujan-Fryns syndrome (OMIM 309520), is characterized by mild to moderate ID, behavior disorders, tall stature with thin or marfanoid habitus, macrocephaly, facial dysmorphic features, and ACC [Lujan et al., 1984; Schwartz et al., 2007]. OSMKB syndrome (OMIM 249620) is characterized by ID and typical facial features, including blepharophimosis, facial coarsening, thick alae nasi, and triangular face [Verloes et al., 2006]. In the present article, we revisited the phenotype of male and female patients with a nonsyndromic XLID caused by a novel MED12 frameshift mutation with severe clinical consequences.

\section{PATIENTS AND METHODS}

This five generation family (T007) included 10 living affected males and 1 female with severe ID with inheritance consistent with X-linked transmission (Fig. 1). All male patients and most

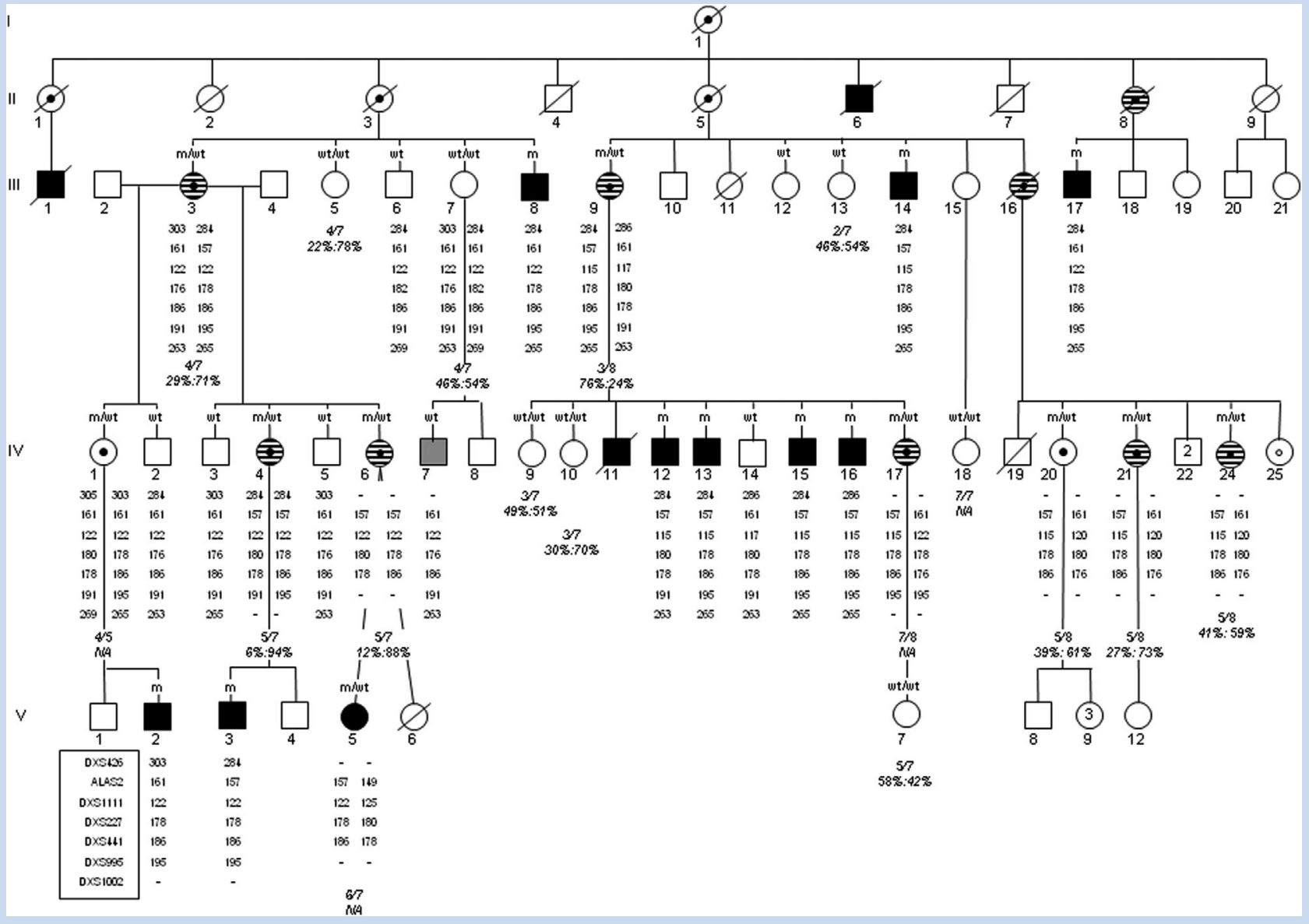

FIG. 1. Pedigree of the family with genetic findings. For the sake of clarity, the pedigree was simplified. Black symbols: intellectual deficiency due to the MED12 mutation. Hatched circles: females known to have borderline to mild cognitive impairment. Circles with a centered black dot: carrier females. Circles with a centered white. Potential carrier females. Gray square: ID not related to the MED12 mutation. Haplotypes of the $\mathrm{Xq13.1}$ region surrounding the $M E D 12$ gene are shown under the symbol of the respective patient as well as the $\mathrm{X}$-chromosome inactivation pattern (italics) when performed. $m=$ mutated allele, $w t=$ wild-type allele. 
heterozygous females were reevaluated clinically after the identification of the MED12 mutation in the family. Cognitive evaluation was performed using the Vineland Adaptive Behavior Scale (VABS) and the Wechsler Adult Intelligence Scale, revision III (WAIS-III). Brain magnetic resonance imaging (MRI) or CT-scan was performed in 5 of the 10 affected males.

Informed consent for genetic studies was obtained for all family members. The linkage study revealed a critical region of approximately $30 \mathrm{cM}$ from Xp11.21 (ALAS2) to Xq22.3 (COL4A5) in seven affected males. One affected male (IV-7) did not share this diseaseassociated haplotype, suggesting that his phenotype could be a phenocopy. This family was then included in a large next generation sequencing project of the EUROMRX consortium aimed at identifying the pathogenic mutations in families with XLID. Genomic DNA ( $3 \mu \mathrm{g}$ ) from the affected male III-14 in Figure 1 was used for constructing a single-end Illumina sequencing library using the Illumina Genomic DNA Single End Sample Prep kit, according to the instructions of the manufacturer. For X-chromosome exome enrichment we used the Agilent SureSelect Human X Chromosome Kit, which contains 47,657 RNA baits for 7,591 exons of the human $\mathrm{X}$ chromosome. Single end deep sequencing was performed on the Illumina Genome Analyzer GAIIx (read-length $76 \mathrm{nt}$ ). Sequencing covered $84 \%$ of the exonic region of the 1,024 genes targeted. Sequences were mapped using RazerS ( $\leq 5$ mismatches) and SplazerS. Variant calling was performed with SNPstore resulting in a total of 2,692 variants. All sequence variants were prioritized by scoring phylogenetic conservation and functional impact (SIFT, PolyPhen2). Confirmation of the MED12 mutation and segregation analysis in the family was done by PCR using a gene-specific primer pair and conventional Sanger sequencing. X-chromosome inactivation (XCI) analysis was performed at the androgen receptor locus with a modification of the assay previously described [Allen et al., 1992]. XCI patterns could be analyzed in 13 of 17 females tested, 7/10 mutation carriers and 6/7 females carrying the wild- type allele. To address the consequences of the c.5898dupC mutation at the cDNA level, RNA was extracted from EBV-immortalized lymphoblastoid cells from Patients III-14 and IV-15. RT-PCR was performed with forward and reverse primers located in exon 40 and 42 , respectively (primers and reaction conditions are available upon request).

Array-CGH was performed in patients IV-7 and $\mathrm{V}-5$ as previously reported [Roll et al., 2010], using a 180,000 (180 K) oligonucleotide microarray (SurePrint G3 Human CGH Microarray Kit, $4 \times 180 \mathrm{~K}$, Agilent Technologies, Santa Clara, CA).

\section{RESULTS}

This family (T007) was included in a large high-throughput next generation sequencing study aiming at identifying the pathogenic mutations in families with XLID collected by the EUROMRX consortium and associated groups. Sequencing of all X-chromosome specific exons from the affected male III-14 in Figure 1 identified a single nucleotide duplication (chrX:70357647 [hg19]) in exon 41 of the MED12 gene (Genbank accession number NM_005120), leading to a frameshift in the C-terminal part of the corresponding protein (p.Ser1967GlnfsX84). This mutations was not detected in publicly available databases, including the 1000 Genomes project database (http://browser.1000genomes.org/index.html), dbSNP135 (http://www.ncbi.nlm.nih.gov/projects/ $\mathrm{SNP} /$ ) and the Exome Variant Server (http://evs.gs.washington. edu/EVS/), nor in $>450 \mathrm{X}$-exomes of index patients from other XLID families (data not shown). Subsequently, the mutation harbored in exon 41 of MED12 was resequenced in 33 family members. The mutation was found in 19 individuals, including 9 males with ID and 10 carrier females. Haplotypes, MED12 gene status, and XCI patterns are shown in Figure 1. Expression studies showed that the mutated allele was not degraded by the non-sensemediated RNA decay in EBV-immortalized lymphoblastoid cells

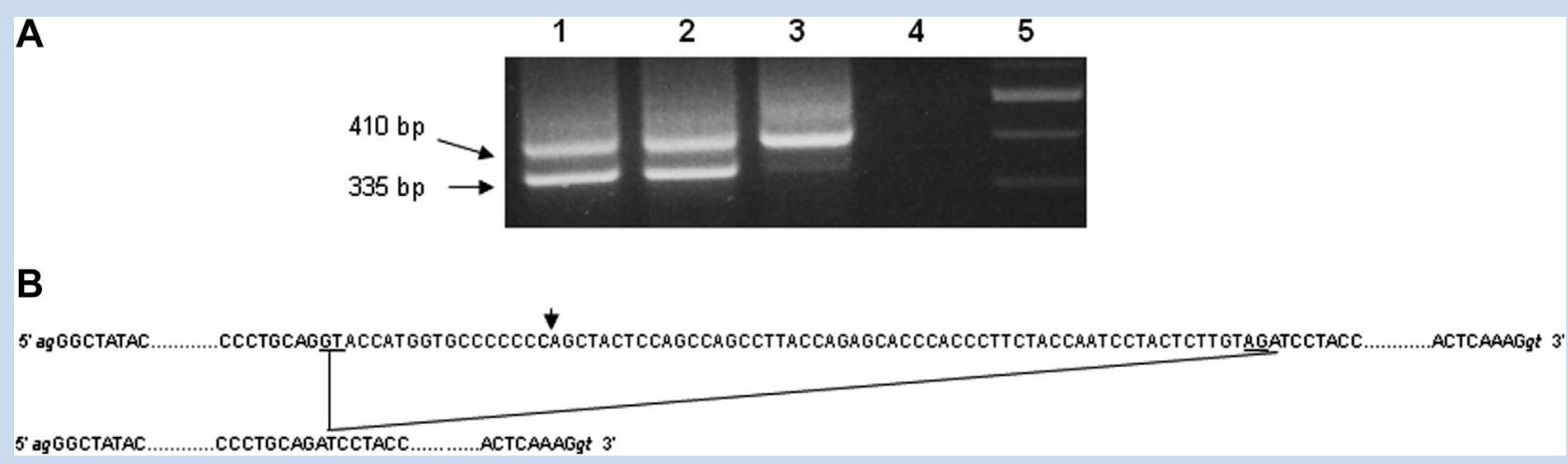

FIG. 2. Consequences of the c.5898dupC at the RNA level. A: Transcript analysis of Patients III1-5 and IV-15. Lane 1 (Patient III-14] and 2 [Patient IV-15] obtained from EBV-immortalized lympoblastoid cells: full-length RT-PCR fragments covering exons 40-42 [410 bp] and abnormal RT-PCR fragment ( 335 bp) lacking 75 bp in exon 41. Lane 3: Control individual. Lane 4: Negative RT-PCR control. Lane 5: 100 pb ladder. B: Nucleotide sequence of exon 41. The mutation c.5898dupC (bold arrow) promotes the use of cryptic $5^{\prime}$ and $3^{\prime}$ splice sites [underlined nucleotides] located in exon 41 and the production of an mRNA with a 75 bp in frame deletion. Nucleotides indicated in bold are excised from exon 41. 
and than in can produce an additional abnormal isoform due to the activation of two cryptic splice-sites within exon 41 , and leading to a 75-bp deletion (Fig. 2).

Clinical features for most patients are summarized in Table I and facial morphological features are shown in Figure 3. Cognitive evaluations are reported in Table II. Female patients had no facial dysmorphic features.

\section{Male Patients}

Patient III-1. This patient had profound ID and died at age 32 years of unknown cause. A photograph showed malar hypoplasia, a long narrow face with high nasal bridge and large ears (not shown).

Patient III-8. This 68-year-old patient had profound ID. He had delayed developmental milestones and walked after 3 years of age. He had very limited language skills. He was shy but had a friendly and cooperative personality. He could eat with a spoon and was continent. He had generalized tonic-clonic seizures in childhood. Dysmorphic features included high forehead, flat malar area, high nasal bridge, and short philtrum (Fig. 3A-D).

Patient III-14. This 74-year-old patient had profound ID. He had no verbal skill. He needed help for all current tasks except for eating with a spoon. He was incontinent. He had a friendly and cooperative personality despite very poor interaction skills. He had two clinical seizures in his 50s. He had constant dyskinetic movements of the tongue, the mouth and the head. Dysmorphic features included a thin habitus, high forehead, flat malar area, high nasal bridge, and large ears (Fig. 3E,F).

Patient III-17. This 62-year-old patient had profound ID. He had no verbal skills. He needed help for all daily tasks except for eating with a spoon. He was shy but had a friendly personality. He was anxious and had a strong need for sameness with fixed routines and self-injury behavior when he was stressed. He had stereotypic movements of the head and hands. Dysmorphic features included high forehead, flat malar area, high nasal bridge, short philtrum, and large ears (Fig. 3G,H).

Patient IV-7. This 40-year-old patient was a phenocopy. He had profound ID with limited language skills. He could eat and dress on his own and ride a bike. He liked sameness and had stereotyped movements. He was cooperative despite a shy personality and limited social skills. Height was over +1.5 SD. He had cryptorchism and a curved penis. Dysmorphic features included large forehead, flat malar area, bulbar nasal tip, short philtrum, large mouth, and prognathism (Fig. 3S,T). He had a $17 \mathrm{p} 13.3$

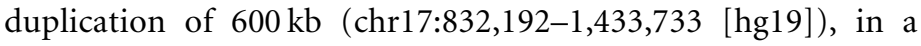
mosaic state. It contained nine genes including YWHAE that encodes 14-3-3. Small duplications encompassing this locus have been reported in patients with a similar phenotype, including ID, overgrowth, and prognathism [Bi et al., 2009; Bruno et al., 2010].

Patient IV-12. This 46-year-old man had profound ID. He could make short sentences with two to three words. He could eat and dress on his own and wash himself with help. He was continent. He had a friendly and cooperative personality with rare bursts of anger or self-aggressiveness. He had left retinal detachment and bilateral cataract and glaucoma. He had stereotypic hand move- ments. Dysmorphic features included high forehead, flat malar area, high nasal bridge, short philtrum, and large ears (Fig. 3I,J).

Patient IV-13. This 44-year-old man patient had profound ID. He could make a few short repetitive sentences. He could dress and wash himself on his own and perform few common daily tasks. He had a friendly and cooperative personality although he was rather shy and anxious. He had drooling and stereotypic movements of the hand and head. Dysmorphic features included high forehead, flat malar area, high nasal bridge, and short philtrum (Fig. 3K,L).

Patient IV-15. This 39-year-old man had profound ID. He had very limited language skills. He could eat with a spoon, dress, and bring back his plate after lunch. He was usually cooperative. He was shy and had a strong need for sameness with repetitive and stereotyped movements and experienced recurrent bursts of aggressiveness. He had a seizure at age 9 years. Dysmorphic features included high forehead, flat malar area, high nasal bridge, short philtrum, and large ears (not shown).

Patient IV-16. This 37-year-old man had profound ID. He had no language skills. He could eat with a spoon but could not perform any other current task. He was incontinent. He had no social interaction. He was rather calm but anxious. He used to put his hand into his throat to make himself vomit. He had dyskinetic movements of the hands. Dysmorphic features included high forehead, flat malar area, high nasal bridge, short philtrum, and large ears (Fig. 3M,N).

Patient V-2. This 19-year-old man had profound ID. He had no verbal skills. He could not perform any daily current task and was incontinent. He had very poor social interactions. He had severe behavior problems with anxiety, hyperactivity, temper tantrums, self-injury and hyperphagia. He had a micropenis. A brain MRI done at 10 months of age showed global moderate cerebral atrophy. Blood karyotype was 47,XYY. Dysmorphic features included high forehead and flat malar area (Fig. 3O,P).

Patient V-3. This 20-year-old man had profound ID. He had limited verbal skills with dysarthric speech. He could eat, dress and wash himself. He was continent. He had a friendly and cooperative personality but was anxious and needed sameness. He had occasional burst of self-injury or aggressiveness. Dysmorphic features included hypotonic face, strabismus, high forehead, flat malar area, high nasal bridge, and short philtrum (Fig. 3Q,R).

\section{Carriers}

Patient III-3. This 75-year-old woman was not considered intellectually impaired. She was autonomous for all daily tasks and was taking care of her daughter (IV-6) and her grand daughter (V-5). Cognitive evaluation showed borderline IQ with lower scores for verbal tasks and low working memory. She had a moderately skewed XCI pattern (29\%:71\%) and it could not be determined which allele was preferentially inactivated.

Patient III-9. This patient was considered as having mild ID with obsessive-compulsive behavior. She had a moderately skewed XCI pattern (24\%:76\%). It could not be determined which allele was preferentially inactivated.

Patient IV-1. She was not considered to be intellectually impaired and she declined cognitive testing. XCI pattern could not be established. 


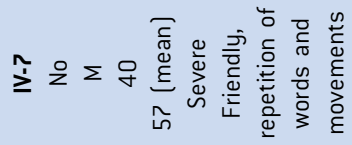

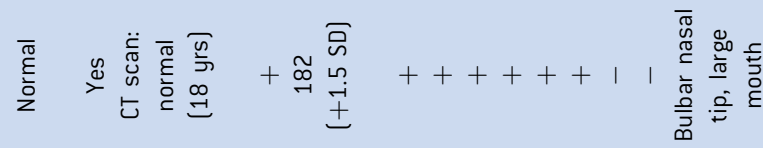

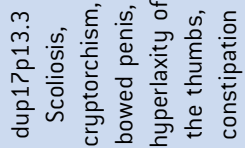

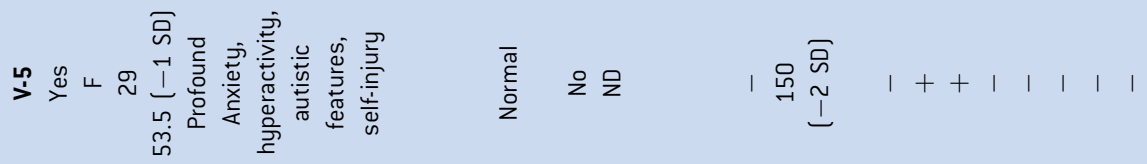

$\overline{\xi^{\bar{g}}}$

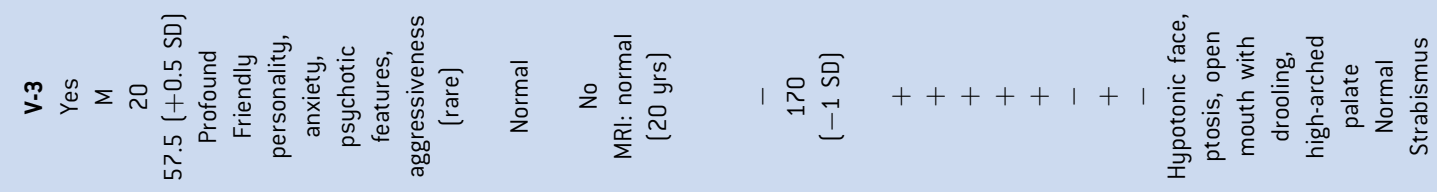

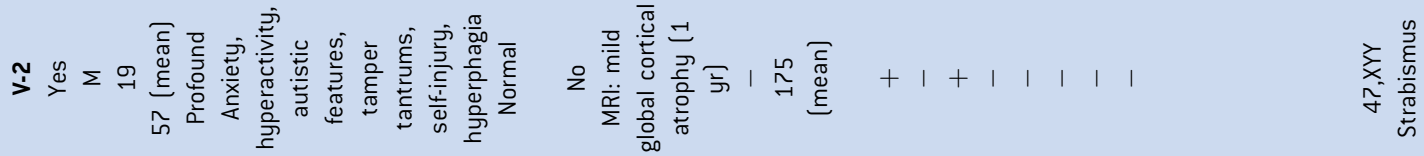

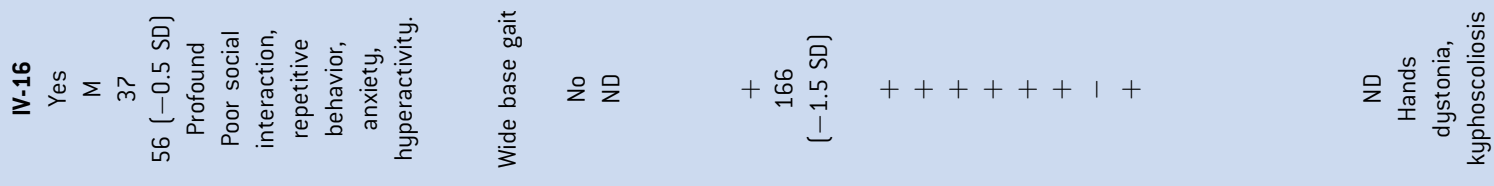

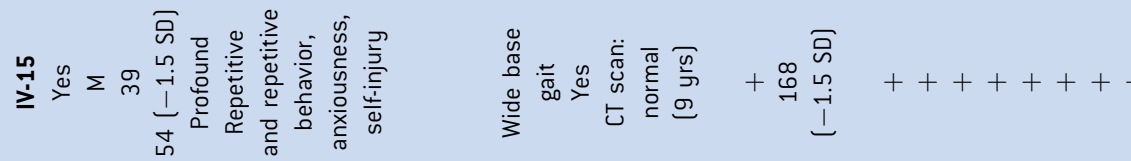

운

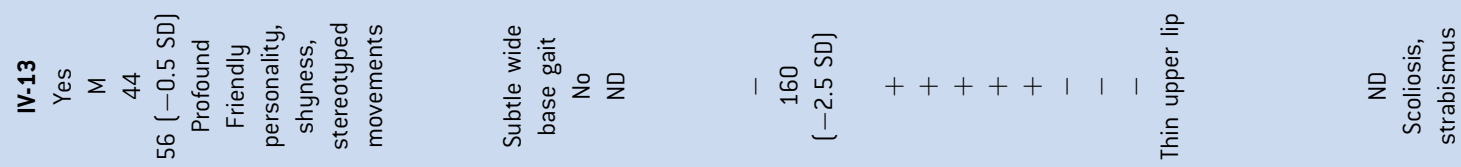

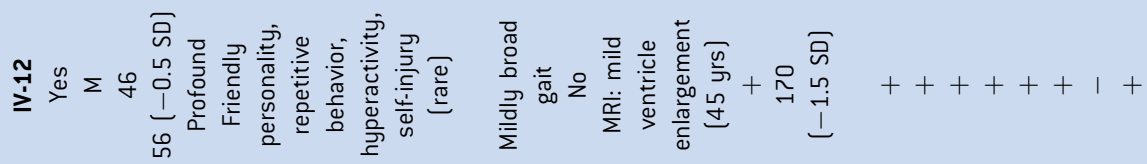

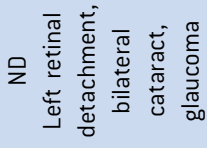

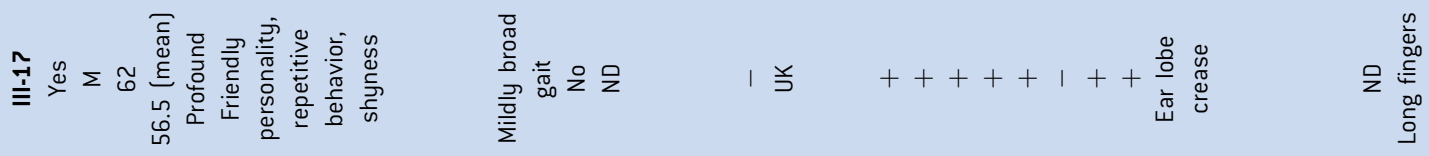

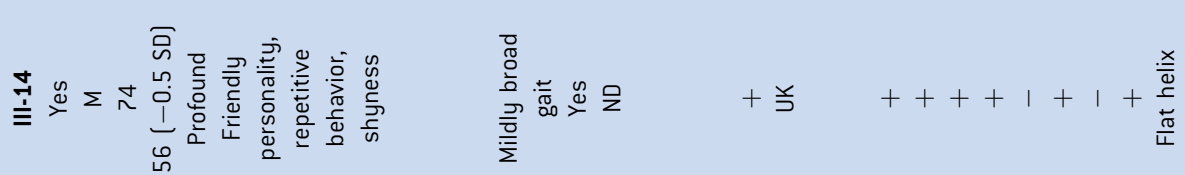

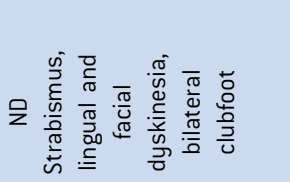

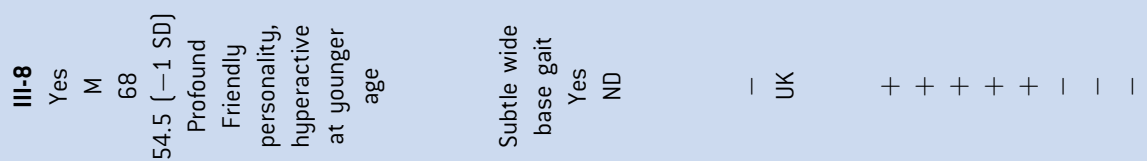

$\sum \frac{\stackrel{0}{\frac{0}{2}}}{\frac{0}{\pi}}$

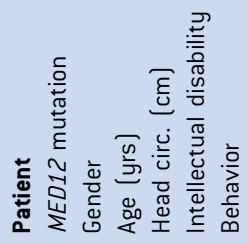

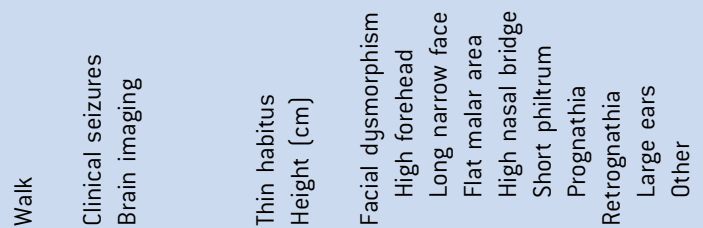

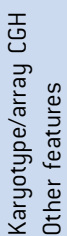




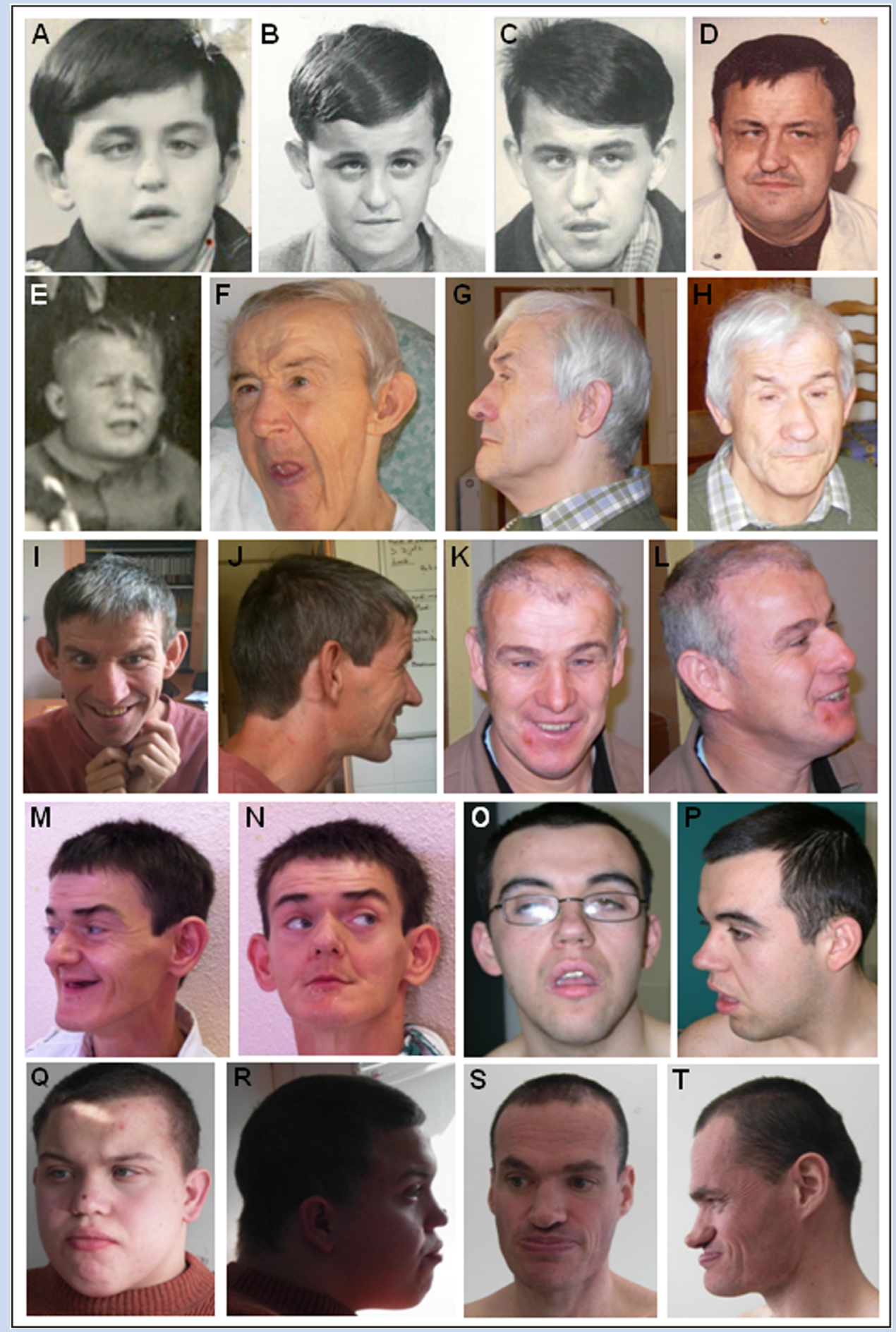

FIG. 3. Photographs of several affected males of the family. A-D: Patient III-8 at different ages. E,F: Patient III-14 when he was a child at now. G,H: Patient III-17. I,J: Patient IV-12. K,L: Patient IV-13. M,N: Patient IV-16. O,P: V-2. Q,R: Patient V-3. S,T: Patient IV-?.

Patient IV-4. This 52-year-old patient had poor school performances and was working in a protected position as a cleaning agent. She had cataracts at age 45 years, of unknown cause. Psychometric evaluation showed a homogeneous pattern of borderline to mild ID with low working memory index. She had a highly skewed XCI pattern (6\%:94\%) with the maternal mutated allele almost exclusively inactivated.

Patient IV-6. This 53-year-old patient had special educational needs. She worked as a cleaning agent in a public school. Psychometric evaluation showed a homogeneous pattern of mild ID. She 


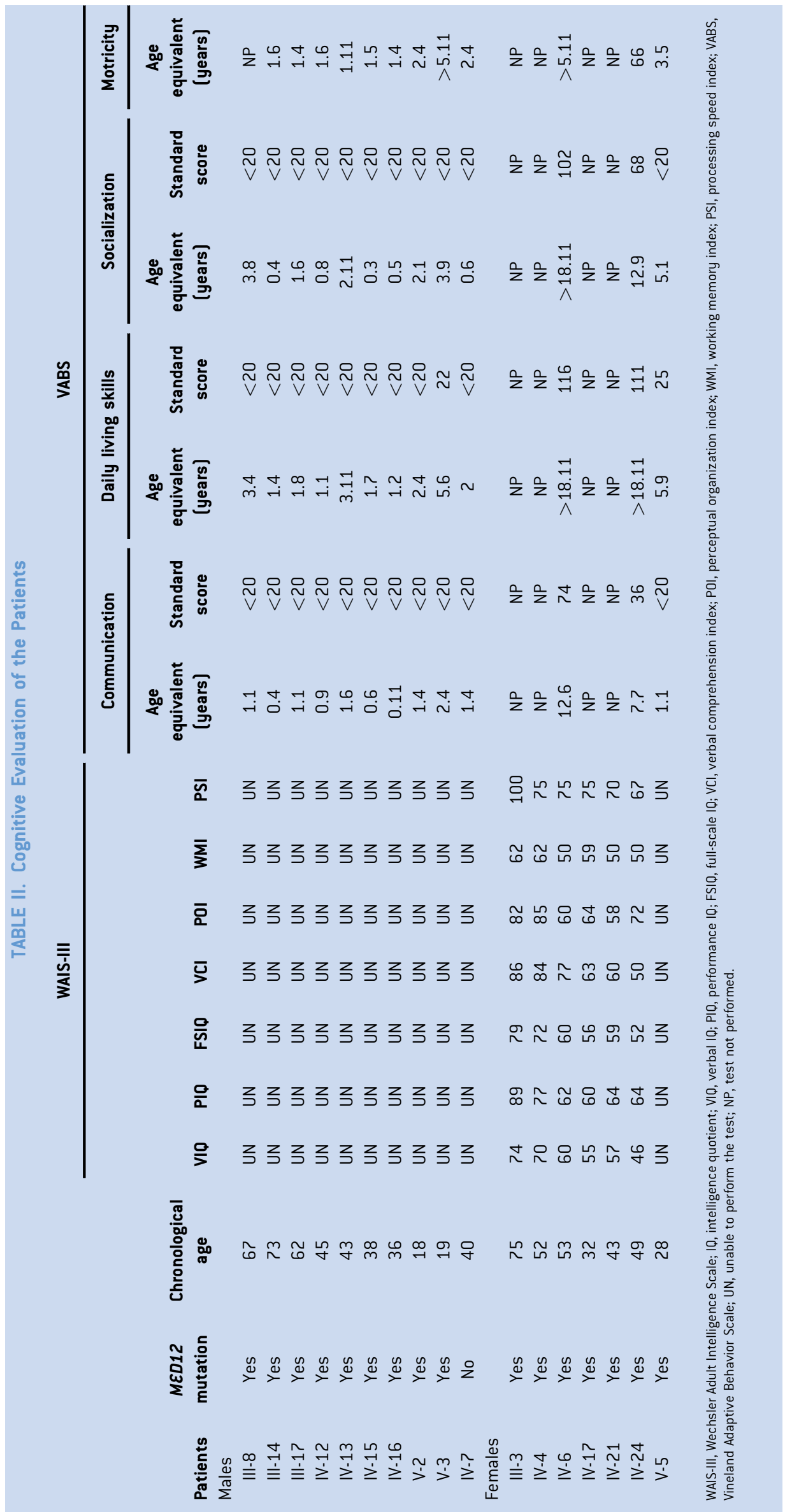


had a skewed XCI pattern (12\%:88\%) and the maternal mutated allele was preferentially inactivated.

Patient IV-17. This 33-year-old woman had limited education. She was working in a restaurant but had difficulties taking care of her daughter. She had an anxious personality with limited social skills. Psychometric evaluation showed a homogeneous pattern of mild ID. Brain MRI done at 32 years of age was normal. XCI pattern could not be established.

Patient IV-20. This patient was not considered to have any cognitive problem. She declined psychometric evaluation. She had a random XCI pattern.

Patient IV-21. This 44-year-old patient had special educational needs. She was an employee of the National Railway Company. She complained about difficulties writing, performing mental arithmetic, and planning daily tasks. Psychometric evaluation showed mild ID with lower scores for verbal tasks. She had a moderately skewed XCI pattern (27\%:73\%) and it could not be determined which allele was preferentially inactivated.

Patient IV-24. This 50-year-old patient had mildly delayed psychomotor development. She worked in a cafeteria but needed help for every complex task and was under guardianship. She was shy. Psychometric evaluation showed moderate ID with more severe impairment on verbal tasks. Brain MRI done at 49 years of age was normal. She had a random XCI pattern (41\%:59\%).

Patient V-5. This 29-year-old patient was profoundly intellectually impaired. She was born at 6 months of pregnancy and her twin sister died at birth. She had psychomotor delay. She had very limited verbal skills. She was hyperactive, anxious, and needed sameness with fixed routines. She had social contact avoidance, compulsive component, and self-injury episodes. Cognitive evaluation showed profound ID. X inactivation study could not be analyzed. She had two alleles with normal FMR1 CGG repeats and array-CGH did not show any chromosomal imbalance.

\section{DISCUSSION}

Up to now, 10 FGS unrelated families have been reported with the p.Arg961Trp mutation and one additional family with the $p$. Gly958Glu mutation whereas the p.Asn1007Ser mutation was found in two families with LS [Schwartz et al., 2007; Risheg et al., 2007; Rump et al., 2011]. Recently, three different missense mutations (p.Arg1148His, p.Ser1165Pro, and p.His1729Asn) were reported in patients with OSMKB [Vulto-van Silfhout et al., 2013].

Despite the reported wide clinical variability reported, patients with MED12 mutations, including those from the family described here, share a common phenotypic pattern of ID, behavior troubles, and dysmorphism. The common core of dysmorphic features, which are rather non-specific, includes long narrow face, tall forehead, high nasal root, and short philtrum. Other features observed in some of the affected males from the present family, such as prominent ears and thin habitus, have been inconsistently observed in patients with MED12 mutations. Neither ACC or dysgenesis of the corpus callosum, which is considered a major criterion for FGS/LS, nor other congenital malformations that were commonly reported in FGS, were observed in the present family [Schwartz et al., 2007; Clark et al., 2009; Rump et al., 2011]. In previously reported MED12related families, cognitive impairment was variable, even when comparing individuals from the same family, from borderline to severe. Individuals affected with FGS/LS usually have an easygoing and affable personality contrasting with anxiety, obsessive-compulsive behavior as well as episodes or longstanding behavior patterns of impulse, aggressiveness, and self-injury [Schwartz et al., 2007; Graham et al., 2008]. Patients from the present family share this common behavior pattern although they all had profound ID. Patient V-2, who had the most important behavior troubles and a higher stature compared to other affected males, also had a supernumerary Y chromosome. XYY males were shown to be often taller and to have depressed verbal IQ relative to their social background, as well as temper tantrum [Leggett et al., 2010]. This chromosomal anomaly may have played a synergic role with the MED12 mutation in the phenotype of this patient.

In addition, heterozygous females from the present family who had cognitive evaluation showed limited abilities despite good adaptation to their social environment, except V-5 who had profound ID and behavior troubles similar to her male counterparts. In this latter patient, premature birth may have played an additional deleterious role on neurodevelopment. No XCI profile difference was observed between non-mutated and mutated females who displayed the variable range of XCI profiles found in the general population. No correlation with the phenotypes could be observed in carrier females (IV-20 had no cognitive problems and IV-24 showed moderate ID, both of them had a random XCI profile). In contrast with the family we describe, ID is not a common feature in females from FGS, LS, and OSMKB families [Schwartz et al., 2007; Clark et al., 2009; Vulto-van Silfhout et al., 2013]. A single carrier female was reported to have mild learning problems but no cognitive evaluation was provided [Rump et al., 2010].

MED12 encodes the largest component of the mediator complex that integrates and conveys regulatory signals by physically linking transcriptional activators or repressors to the basal RNA Pol II transcriptional assembly [Philibert and Madan, 2007]. The four missense mutations that have been assayed (p.Arg961Trp, p.Asn1007Ser, p.Arg1148His, and p.Ser1165Pro) were shown to have partial consequences on MED12 function, whereas it was fully abolished by terminal deletions [Ding et al., 2008; Vulto-van Silfhout et al., 2013]. The c.5898dupC mutation found in the present family, was shown to escape non-sense-mediated RNA decay and to produce two abnormal mRNAs: the first one with the frameshift and the other one with an in-frame 75-bp deletion due to the activation of two cryptic splice sites in exon 41 . The more severe degree of ID in patients from the present family compared to the other MED12-related phenotypes, and the occurrence of cognitive impairment in heterozygous females suggests that this mutation has a more severe effect than the missense mutations previously reported.

In this article, we show that MED12 mutations may be associated with profound ID and non-specific and variable dysmorphic features variable in males and with significant degree of cognitive impairment in some heterozygous females. 


\section{ACKNOWLEDGMENTS}

We thank Melanie Bienek for her excellent technical assistance. This work has been financed by a grant of the German Ministry of Education and Research through the MRNET (Grant 01GS08161 to H.H.R) and by the Project GENCODYS (241995, H.H., V.M.K., H.H.R.), which is funded by the European Union Framework Program 7 (FP7).

\section{REFERENCES}

Allen RC, Zoghbi HY, Moseley AB, Rosenblatt HM, Belmont JW. 1992. Methylation of HpaII and HhaI sites near the polymorphic CAG repeat in the human androgen-receptor gene correlates with $\mathrm{X}$ chromosome inactivation. Am J Hum Genet 51:1229-1239.

Bi W, Sapir T, Shchelochkov OA, Zhang F, Withers MA, Hunter JV, Levy T, Shinder V, Peiffer DA, Gunderson KL, Nezarati MM, Shotts VA, Amato SS, Savage SK, Harris DJ, Day-Salvatore DL, Horner M, Lu XY, Sahoo T, Yanagawa Y, Beaudet AL, Cheung SW, Martinez S, Lupski JR, Reiner O. 2009. Increased LIS1 expression affects human and mouse brain development. Nat Genet 41:168-177.

Bruno DL, Anderlid BM, Lindstrand A, van Ravenswaaij-Arts C, Ganesamoorthy D, Lundin J, Martin CL, Douglas J, Nowak C, Adam MP, Kooy RF, Van der Aa N, Reyniers E, Vandeweyer G, Stolte-Dijkstra I, Dijkhuizen T, Yeung A, Delatycki M, Borgström B, Thelin L, Cardoso C, van Bon B, Pfundt R, de Vries BB, Wallin A, Amor DJ, James PA, Slater HR, Schoumans J. 2010. Further molecular and clinical delineation of co-locating 17p13.3 microdeletions and microduplications that show distinctive phenotypes. J Med Genet 47:299-311.

Clark RD, Graham JM Jr, Friez MJ, Hoo JJ, Jones KL, McKeown C, Moeschler JB, Raymond FL, Rogers RC, Schwartz CE, Battaglia A, Lyons MJ, Stevenson RE. 2009. FG syndrome, an X-linked multiple congenital anomaly syndrome: The clinical phenotype and an algorithm for diagnostic testing. Genet Med 11:769-775.

Ding N, Zhou H, Esteve PO, Chin HG, Kim S, Xu X, Joseph SM, Friez MJ Schwartz CE, Pradhan S, Boyer TG. 2008. Mediator links epigenetic silencing of neuronal gene expression with $\mathrm{x}$-linked mental retardation. Mol Cell 31:347-359.

Graham JM Jr, Visootsak J, Dykens E, Huddleston L, Clark RD, Jones KL, Moeschler JB, Opitz JM, Morford J, Simensen R, Rogers RC, Schwartz CE, Friez MJ, Stevenson RE. 2008. Behavior of 10 patients with FG syndrome (Opitz-Kaveggia syndrome) and the p.R961W mutation in the MED12 gene. Am J Med Genet Part A 146A:3011-3017.
Leggett V, Jacobs P, Nation K, Scerif G, Bishop DV. 2010. Neurocognitive outcomes of individuals with a sex chromosome trisomy: XXX, XYY, or XXY: A systematic review. Dev Med Child Neurol 52:119-129.

Lujan JE, Carlin ME, Lubs HA. 1984. A form of X-linked mental retardation with marfanoid habitus. Am J Med Genet 17:311-322.

Opitz JM, Kaveggia EG. 1974. Studies of malformation syndromes of man 33: The FG syndrome. An X-linked recessive syndrome of multiple congenital anomalies and mental retardation. Z Kinderheilkd 117:1-18.

Philibert RA, Madan A. 2007. Role of MED12 in transcription and human behavior. Pharmacogenomics 8:909-916.

Risheg H, Graham JM Jr, Clark RD, Rogers RC, Opitz JM, Moeschler JB, Peiffer AP, May M, Joseph SM, Jones JR, Stevenson RE, Schwartz CE, Friez MJ. 2007. A recurrent mutation in MED12 leading to R961W causes Opitz-Kaveggia syndrome. Nat Genet 39:451-453.

Roll P, Sanlaville D, Cillario J, Labalme A, Bruneau N, Massacrier A, Délepine M, Dessen P, Lazar V, Robaglia-Schlupp A, Lesca G, Jouve E, Rudolf G, Rochette J, Lathrop GM, Szepetowski P. 2010. Infantile convulsions with paroxysmal dyskinesia (ICCA syndrome) and copy number variation at human chromosome 16p11. PLoS ONE 5:e13750.

Ropers HH. 2008. Genetics of intellectual disability. Curr Opin Genet Dev $18: 241-250$

Rump P, Niessen RC, Verbruggen KT, Brouwer OF, de Raad M, Hordijk R. 2011. A novel mutation in MED12 causes FG syndrome (Opitz-Kaveggia syndrome). Clin Genet 79:183-188.

Schwartz CE, Tarpey PS, Lubs HA, Verloes A, May MM, Risheg H, Friez MJ, Futreal PA, Edkins S, Teague J, Briault S, Skinner C, Bauer-Carlin A, Simensen RJ, Joseph SM, Jones JR, Gecz J, Stratton MR, Raymond FL, Stevenson RE. 2007. The original Lujan syndrome family has a novel missense mutation (p.N1007S) in the MED12 gene. J Med Genet 44: $472-477$.

Verloes A, Bremond-Gignac D, Isidor B, David A, Baumann C, Leroy MA, Stevens R, Gillerot Y, Héron D, Héron B, Benzacken B, Lacombe D, Brunner H, Bitoun P. 2006. Blepharophimosis-mental retardation (BMR) syndromes: A proposed clinical classification of the so-called Ohdo syndrome, and delineation of two new BMR syndromes, one X-linked and one autosomal recessive. Am J Med Genet Part A 140A: 1285-1296.

Vulto-van Silfhout AT, de Vries BBA, van Bon BWM, Hoischen A, Ruiterkamp-Versteeg M, Gilissen C, Gao F, van Zwam M, Harteveld CL, van Essen AJ, Hamel BCJ, kleefstra T, Willemsen MA, Yntema HG, van Bokhoven H, Brunner HG, Boyer TG, de Brouwer APM. 2013. Mutations in MED12 cause X-linked Ohdo syndrome. Am J Hum Genet 92:401-406 